\title{
Fasiyal sinir dekompresyonu: 44 hastadaki sonuçlarımız
}

\author{
Facial nerve decompression: Our results in 44 patients
}

\author{
Berat Demir $(\mathbb{D}$, Adem Binnetoğlu $(1)$ \\ Marmara Üniversitesi Tıp Fakültesi Kulak Burun Boğaz Hastalkları Anabilim Dalı, İstanbul, Türkiye
}

\section{$\ddot{O} Z$}

Amaç: Bu çalışmada, intratemporal periferik fasiyal paralizisi (PFP) olan hastalarda transmastoid fasiyal sinir dekompresyon cerrahisi sonuçları ve etkinliği değerlendirildi.

Hastalar ve Yöntemler: Çalışmaya Ocak 2000 - Ocak 2016 tarihleri arasında çeşitli etyolojilere bağlı intratemporal PFP olan 44 hastanın (25 erkek, 19 kadın; ort. yaş 43 yıl; dağılım, 2.5-78 yıl) transmastoid fasiyal sinir dekompresyonu sonuçları dahil edildi.

Bulgular: Hastaların 19'unda (\%41.3) Bell paralizisine bağlı, 19'unda (\%41.3) kronik otitis mediaya (KOM) bağlı, altısında (\%13) travmatik ve ikisinde (\%4.3) iyatrojenik PFP vardı. Travmatik PFP'li hastaların \%67'sinde, KOM'ye bağlı PFP'lilerin \%84'ünde, iyatrojenik PFP'lilerin \%67'sinde ve Bell paralizisine bağlı PFP'lilerin tamamında fasiyal sinir fonksiyonlarında tatmin edici iyileşme saptandı. İyatrojenik olan ve anastomoz yapılan iki hastada da yüzgüldürücü sonuçlar elde edildi. Komplikasyonlar bir hastada orta sensorinöral işitme kaybı, beş hastada kondüktif işitme kaybı ve bir hastada karma işitme kaybını içerdi.

Sonuç: Fasiyal sinir dekompresyonu ciddi fasiyal sinir paralizisi olan hastalarda ve ilaç tedavisiyle yeterli iyileşmesi olmayanlarda daha hızlı ve üstün fonksiyonel iyileşme sağladı.

Anahtar sözcükler: Fasiyal dekompresyon; fasiyal paralizi; periferik fasiyal paralizi; cerrahi; transmastoid fasiyal sinir dekompresyonu.

Fasiyal sinir yüz kaslarımızı innerve ederek bizim ruh halimizi ve duygularımızı ifade etmemizi sağlar. Motor, sekretuar, sensöriyal ve sensitif sinir liflerinden oluşan fasiyal sinir karma bir kraniyal sinirdir. ${ }^{[1]}$

\begin{abstract}
Objectives: This study aims to evaluate the results and effectiveness of transmastoid facial nerve decompression surgery in patients with intratemporal peripheral facial paralysis (PFD).

Patients and Methods: The study included results of transmastoid facial nerve decompression of 44 patients ( 25 males, 19 females; mean age 43 years; range, 2.5 to 78 years) who had intratemporal PFP due to various etiologies between January 2000 and January 2016.

Results: Of the patients, 19 (41.3\%) had Bell's paralysis-induced, 19 (41.3\%) had chronic otitis media (COM)-induced, six (13\%) had traumatic, and two (4.3\%) had iatrogenic PFP. Significant recovery was detected in facial nerve functions in $67 \%$ of patients with traumatic PFP, in $84 \%$ of those with COM-induced PFP, in $67 \%$ of those with iatrogenic PFP, and in all of those with Bell's paralysis-induced PFP. Two patients with iatrogen PFP and undergone anastomosis had satisfactory results. Complications included moderate sensorineural hearing loss in one patient, conductive hearing loss in five patients and mixed hearing loss in one patient.
\end{abstract}

Conclusion: Facial nerve decompression provided more rapid and superior functional recovery in patients with severe facial nerve paralysis and those with no sufficient recovery with medical treatment.

Keywords: Facial decompression; facial palsy; peripheral facial paralysis; surgery; transmastoid facial nerve decompression.

Fasiyal sinir 7.000'i motor olmak üzere yaklaşık 10.000 kadar sinir lifinden oluşur. ${ }^{[2]}$ Periferik fasiyal paralizi (PFP)'lerinin \%90'ı intratemporal bölgede görülmektedir. $^{[3]}$ Fasiyal sinir paralizisi travma veya tümör gibi

Gelis tarihi: 12 Haziran 2018 Kabul tarihi: 02 Ağustos 2018

İletişim adresi: Dr. Berat Demir. Marmara Üniversitesi Pendik Eğitim ve Araştırma Hastanesi, Kulak Burun Boğaz Hastalıkları Anabilim Dalı, 34899 Pendik, İstanbul, Türkiye. Tel: 0507 - 4901182 e-posta: drberatdemir80@hotmail.com 
birçok farklı nedenle olabildiği gibi idiyopatik de olabilir. İntratemporal PFP'nin \%65'inde idiyopatik olarak adlandırılan Bell paralizisi görülmektedir. Bell paralizisinde cerrahinin yeri ve zamanı konusunda fikir birliği yoktur. Bell paralizisinde en çok uygulanan cerrahi yöntem intratemporal fasiyal sinir dekompresyonudur. ${ }^{[4]}$ Intratemporal fasiyal sinir dekompresyonu Bell paralizi ile birlikte otitis media, travmatik ve iyatrojenik fasiyal paralizilerde de uygulanır. Travmaya bağlı PFP'de cerrahi tedavide paralizinin ortaya çıkma zamanına, topografik test sonuçlarına ve lezyonun yerine göre karar verilirken kronik otitis mediada (KOM) ve iyatrojenik nedenlere bağlı PFP'lerde ise acil cerrahi dekompresyon yapılır. Çalışmamızda Bell paralizisi, travmatik, otojen ve iyatrojenik nedenlerle oluşan PFP hastalarında transmastoid fasiyal sinir dekompresyon sonuçları sunuldu.

\section{HASTALAR VE YÖNTEMLER}

Marmara Üniversitesi Tip Fakültesi Hastanesi KBB Anabilim Dalına Ocak 2000 - Ocak 2016 tarihleri arasında Bell paralizisi, travmatik, otojen ve iyatrojenik nedenlerle oluşan PFP görülen 44 hastaya (25 erkek, 19 kadın; ort. yaş 43 yıl; dağılım $2.5-78$ yıl) transmastoid fasiyal sinir dekompresyonu yapild. Fasiyal sinirin fonksiyonunu değerlendirmek House-Brackmann (HB) derecelendirme için sistemi kullanıld..$^{[5]}$ Bizim çalışmamızda da Bell paralizisi başlangıcından sonra elektronörografi (ENoG)'de \%90'dan fazla dejenerasyonu olan ve elektromiyografi (EMG)'de istemli potansiyeli olmayan 18 hastaya 21-70 gün boyunca (ortalama 50 gün) transmastoid yaklaşım ile cerrahi dekompresyon uygulandı. On yedi hastanın sağ tarafında bir hastanın ise sol tarafta, aynı hastanın bir yıl sonra sağ tarafta da Bell paralizisi görüldü. Tüm hastalara cerrahi öncesi

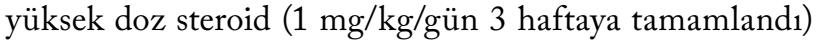
ve antiviral tedavi (asiklovir $1000 \mathrm{mg} / \mathrm{kg} / \mathrm{gün} 5$ gün) verildi. Hastaların tümünde tedaviye dirençli PFP görüldü ve tüm hastalar en az altı ay takip edildi. Travma sonucu erken dönemde PFP ortaya çıkan bir hasta; ayrıntılı fizik muayene, odyolojik testler ve bilgisayarlı tomografi ile değerlendirildi. Kırık hattı, kulak zarı muayeneleri, odyogramları kaydedildi. On dört hastada EMG'ye, beşinde ise ENoG'ye göre paraliziden 3-30 gün (ortalama 14 gün) sonra dekompresyon yapıldı. Kronik otitis mediaya bağlı olarak PFP gelişen 19 hasta fizik muayene, odyolojik testler ve bilgisayarlı tomografi ile değerlendirildi. Kolesteatom nedeniyle bir hastanın sağ kulağına dekompresyon yapıldıktan bir yıl sonra yine kolesteatom nedeniyle PFP gelişti. İki hastada koklear implant cerrahisi sonrası posterior timpanotomiye bağl1 olarak PFP gelişti ve acil fasiyal dekompresyon ile birlikte sinir onarımı yapıld 1 (Tablo 1 ).

\section{Cerrahi teknik}

Fasiyal sinir tüm hastalarda transmastoid yaklaşım ile genel anestezi altında genikulat gangliyon ile stilomastoid foramen arasında tamamen serbestleştirildi. Bunu takiben fallop kanalı açıldı, gerekli görülenlerde sinir kılıfı da açılarak dekomprese edildi. Sinirde tam kesi olan iki hastada great auriküler sinir grefti ile anastomoz yapıldı. Serbestleştirilen sinirin üzerine temporal kas fasiyasından alınan greft serildi. Hastalar ilk altı ay içinde ayda bir, daha sonra altı ayda bir kontrole çağrılarak paralizinin klinik olarak iyileşmesi (Alın çizgilerinin durumu, gözü sıkıca kapama, sslık çalma, dudak hareketleri, dişleri gösterme gibi motor hareketler) değerlendirildi. İyileşmenin değerlendirilmesinde House ve Brackmann tarafından düzenlenen kriterler kullanıldı (Tablo 2). ${ }^{[5]}$

\section{BULGULAR}

Kırk dört hastanın 18'inde (\%41.3) tüm araştırmalara rağmen neden belirlenemedi ve bu hastalar Bell paralizisi olarak kabul edildi. On sekiz hastanın birinde diğer tarafta da Bell paralizisi görüldü. Bir hastada karşı tarafta altı ay sonra PFP görüldü. Bell paralizili hastaların hepsinde sinirde ödem ve konjesyon varlığ 1 tespit edildi.

Kronik otitis mediaya bağlı PFP gelişen hastaların ikisinde ileri derecede sensörinöral işitme kaybı (SNİK), 16’sında iletim tipi işitme kaybı (İTİK), altısında ise her

\begin{tabular}{|lcccc|}
\hline \multicolumn{5}{|c|}{ Tablo 1 } \\
\multicolumn{5}{|c|}{ Periferik fasiyal paralizilerde etyoloji ve lezyon tarafı } \\
\hline Etyoloji & Sayı & Yüzde & Sağ & Sol \\
\hline Travma & 6 & 13.00 & 4 & 2 \\
Bell paralizi & 19 & 41.30 & 12 & 7 \\
Kronik otitis mediada komplikasyon & 19 & 41.30 & 8 & 11 \\
İyatrojen & 2 & 4.30 & - & 2 \\
Toplam & $46^{*}$ & 100 & 24 & 22 \\
\hline${ }^{*}$ 44 hasta, 46 kulak. & & & & \\
\hline
\end{tabular}




\begin{tabular}{|c|c|c|}
\hline \multicolumn{3}{|c|}{$\begin{array}{c}\text { Tablo } 2 \\
\text { House-Brackmann evreleme sistemi }\end{array}$} \\
\hline Grade I & Normal & Normal fasiyal sinir fonksiyonu \\
\hline Grade II & Hafif disfonksiyon & $\begin{array}{l}\text { Dikkatli muayene ile saptanabilen hafif bir parezi vardır. } \\
\text { İstirahat halinde normal simetri ve tonus vardır. } \\
\text { Alın hareketi orta iyi derecedir. Göz minimal eforla kapanabilir. } \\
\text { Hafif ağız asimetrisi vardır. Hafif sinkinezi bulunabilir. }\end{array}$ \\
\hline Grade III & Orta disfonksiyon & $\begin{array}{l}\text { Yüzün her iki yarısı arasında bariz ancak görünümü bozmayan asimetri } \\
\text { vardır. İstirahat halinde normal simetri ve tonus vardır. Alın hareketi hafif } \\
\text { orta derecedir. Göz eforla tam kapanabilir. Maksimum eforla hafif bir ağız } \\
\text { hareketi oluşur. Fark edilen ancak ağır olmayan derecede sinkinezi, } \\
\text { kontraktür veya hemifasiyal spazm vardır. }\end{array}$ \\
\hline Grade IV & Orta ağır disfonksiyon & $\begin{array}{l}\text { Yüzün her iki yarısı arasında bariz veya görünümü bozan asimetri vardır. } \\
\text { İstirahat halinde normal simetri ve tonus vardır. Alın hareketi yoktur. } \\
\text { Göz kapanması inkomplettir. Maksimum eforla asimetrik bir ağız } \\
\text { görünümü oluşur. }\end{array}$ \\
\hline Grade V & Ağır disfonksiyon & $\begin{array}{l}\text { Sadece belli belirsiz bir kas hareketi vardır. İstirahatte asimetri vardır. } \\
\text { Alın hareketi yoktur. Göz kapanması inkomplettir. Ağız çok hafif hareket eder. }\end{array}$ \\
\hline Grade VI & Total paralizi & Çok belirgin asimetri vardır. Kas hareketi yoktur. \\
\hline
\end{tabular}

iki kulakta KOM tespit edildi. Hastaların 12'sine kanal wall-down mastoidektomi yapilırken, altısına radikal mastoidektomi yapıldı. Hiçbir hastada sinir kesisi gözlenmemekle birlikte ileri derecede ödem ve enflamasyon tespit edildi. Bu hastaların 14'ünde sinir kılıfi aç1lırken beşinde sinir bütünlüğü korundu (Tablo 3). Fallop kanalı dehissansı en sık (\%84) timpanik segmentte idi. Üç kulakta (\%16) mastoid segmentte dehissans izlendi. Genikulat gangliyon düzeyinde herhangi bir patoloji görülmedi (Tablo 4).

Üç hastada kolesteatomun labirentin içine girmesi nedeniyle parsiyel labirentektomi yapild 1 ve kolesteatom temizlendi. Bu bölge daha sonra kas ve fasya ile ayrıca onarild.

Travmatik PFP altı hastanın (3 erkek, 3 kadın) dördünde longitudinal, ikisinde transvers temporal kemik kırığı tespit edildi. Hastaların dördünde trafik kazası, ikisinde yüksekten düşme öyküsü vardı. Bu hastaların kulak zarı muayene bulguları Tablo 5'de belirtildi. Tüm hastalarda ödem veya hematom vardı. Travmatik PFP hastalarının birinde fallop kanalında kırık ve üçünde fasiyal sinirin timpanik segmentinde patoloji görülürken, ikisinde timpanik ve mastoid segment normaldi. Fasiyal sinirde ödem veya hematom tespit edilen hastalarda sinir kılıfı açılarak dekompresyon sağlandı. Hiçbir patoloji tespit edilemeyen hastalarda lezyonun labirent segmentte olduğu düşünülerek kontrole alındı (Tablo 6).

\begin{tabular}{|lc|}
\hline \multicolumn{2}{|c|}{$\begin{array}{c}\text { Tablo 3 } \\
\text { Kronik otitis mediada ameliyat bulguları }\end{array}$} \\
\hline Bulgular & Sayı \\
\hline Fallop kanalında defekt & 19 \\
Fasiyal sinirde ödem, enfeksiyon & 19 \\
Kolesteatom & 12 \\
Granülasyon, polip & 5 \\
\hline
\end{tabular}

\begin{tabular}{|lcc|}
\hline \multicolumn{3}{|c|}{$\begin{array}{c}\text { Tablo 4 } \\
\text { Kronik otitis mediaya bağlı fasiyal paralizi olan hastalarda } \\
\text { ameliyat bulguları }\end{array}$} \\
\hline \multicolumn{2}{|c|}{ Sayı } & Yüzde \\
\hline Ameliyat türü & 12 & 63 \\
Kanal wall-down mastoidektomi & 7 & 37 \\
Radikal mastoidektomi & & \\
Fallop kanalı dehisansı & 16 & 84 \\
Timpanik segment & 3 & 16 \\
Mastoid segment & - & - \\
Genikulat gangliyon & 7 & 36.84 \\
Labirent fistülü & 4 & 21.05 \\
Lateral semisirküler kanal & 2 & 10.52 \\
Süperior semisirküler kanal & 1 & 5.26 \\
Posterior semisirküler kanal &
\end{tabular}




\section{Tablo 5}

Travmatik periferik fasiyal paralizi kulak zarı muayenesi bulguları

\begin{tabular}{|lc|}
\hline Bulgular & Sayı \\
\hline Kulak zarı perforasyonu & 2 \\
Hemotimpanum & 3 \\
İletim tipi işitme kaybı & 4 \\
Sensörinöral işitme kaybı & 1 \\
Multipl travma & 4 \\
Eşlik eden ek kraniyal sinir paralizisi & - \\
\hline
\end{tabular}

Koklear implant cerrahisinden sonra iyatrojenik PFP gelişen iki hastanın fasiyal sinirinde tam kesi vardı. Bunlarda great auriküler serbest sinir grefti anastomozu ile sinir onarımı yapıld. Travmatik PFP'li hastaların \%67'sinde, KOM'ye bağlı PFP olan hastaların \%84'ünde, Bell paralizili hastaların ise hepsinde fasiyal sinir fonksiyonlarında tatmin edici iyileşme tespit edildi. İyatrojenik olan ve anastomoz yapılan iki hastada da yüzgüldürücü sonuçlar elde edildi (Tablo 7). Dekompresyon sonucunda dört hastada hafif orta derecede kalıcı İTİK, bir hastada orta derecede kalıcı SNIK, bir hastada ise mikst tip işitme kaybı gelişti.

\section{TARTIŞMA}

Fasiyal paralizi, ağır kozmetik deformitelere yol açması nedeniyle hem hasta hem de ailesi için zor bir hastalıktır. Göz kapağını kapatamaması ve keratit, mimik fonksiyonlarının bozulması, konuşma ve çiğnemede zorlukların yaşanması hastayı sosyal ve psikolojik açıdan olumsuz etkilemektedir. Bu nedenle PFP klinik ve elektrodiyagnostik testler ile iyi değerlendirilmeli ve medikal veya cerrahi yöntemlerle tedavi edilmelidir. Steroidler sinir üzerinde enflamasyonu azaltarak ve asiklovir ve türevleri gibi antiviral ajanlar ile iyileşmeyi hızlandırabilir. Fasiyal paralizinin medikal ve cerrahi tedavileri konusunda halen kesin bir fikir birliği yoktur. May ve ark. nın ${ }^{[6]}$ Bell felci olan 1011 hastalık çalışmasında, hastaların

\begin{tabular}{|lc|}
\hline \multicolumn{2}{|c|}{ Tablo 6 } \\
Travmatik periferik fasiyal paralizilerde ameliyat bulguları \\
\hline Bulgular & Say1 \\
\hline Fallop kanalında kırık & 1 \\
Fasiyal sinir lezyonu bölümü & \\
Timpanik & 3 \\
Mastoid & - \\
Normal (labirentin segment) & 2 \\
\hline
\end{tabular}

\%84'ünde normal veya normal yüz fonksiyonuna yakın iyileşme elde edilmesine rağmen diğer \%16'sında kötü sonuçlar elde edilmiş ve bu hastalarda ek tedaviye gerek duyulmuştur. Bell paralizisinde, paraliziyi ve prognozun derecesini tahmin etmede ve tedavi yöntemini belirlemede kullanilan objektif testler ENoG ve EMG'dir. Yüz felcinin başlangıcından itibaren 14 gün içinde yapılan ENoG'da \%90'dan fazla dejenerasyon bulgusu olmas1 hastada prognozun kötüye gittiğini göstermektedir. ${ }^{[6,7]}$ Fasiyal sinir dekompresyon cerrahisi komplet fasiyal paralizi ve tam sinir dejenerasyonu olan hastalarda tercih edilebilir ancak Bell paralizisi için cerrahinin avantajları ve endikasyonları kesin değildir. Medikal tedaviye yanıt vermeyen hastalarda cerrahi yapılsa da en uygun zamanlama ve cerrahi bölge halen belirsizdir. Erken dönemde veya ikinci ayda dekompresyon yapılan hastaların iyileşme sonuçlarında hiç bir fark olmadığı bildirilmiştir. ${ }^{[8,9]}$ Gantz ve ark. ${ }^{[10]}$ fasiyal sinir dekompresyonunun cerrahi bölge açısından orta kraniyal fossa tekniği kullanılarak yapılması gerektiğgini bildirmişlerdir. Ancak, orta kafa çukuru yaklaşımı kullanılırken anatomik işaretleri teyit etmek çok zor olabilmektedir. Ayrıca, bu yaklaşım temporal lobun retraksiyon gerektirmemesi, nöbet, afazi ve kafa içi kanama dahil olmak üzere yan etkiler ile ilişkili olduğu düşünülmektedir. Bizim çalışmamızda da, Bell paralizisi başlangıcından sonra ENoG'de \%90'dan fazla dejenerasyonu olan ve EMG'de istemli potensiyeli olmayan 18 hastaya 21-70 gün boyunca (ortalama 50 gün) transmastoid yaklaşım ile cerrahi dekompresyon yapıld 1 ve tüm hastalarda yüz güldürücü sonuç elde edildi.

\begin{tabular}{|lcccc|}
\hline \multicolumn{5}{c|}{ Tablo 7 } \\
& & & \\
\hline Paralizi & Dekompresyon sonucu iyileşme sonuçları & & \\
\hline Bell paralizi & 1. Derece & 2. Derece & 3. Derece & 4. Derece \\
Kronik otitis media komplikasyonu & 6 & 13 & - & - \\
Travmatik & 7 & 9 & 2 & 1 \\
İyatrojenik & 3 & 1 & 1 & 1 \\
Toplam & - & 1 & 1 & - \\
\hline
\end{tabular}


Hiçbir hastada nüks izlenmedi. Bir hastada altı ay sonra karşı tarafta PFP görüldü.

Fasiyal sinir paralizisi özellikle kolesteatomlu KOM'nin en önemli komplikasyonlarından biridir. Paralizinin oluşması, klinik gidişi ve başlangıç ile ameliyat arasında geçen süre ve cerrahinin başarısı hakkında çeşitli görüşler bulunmaktadır. En çok kabul gören görüş hastanın en kısa sürede ameliyata alınması gerektiğidir. ${ }^{[11]}$ May ve ark. ${ }^{[6]}$ otojen PFP'li 52 hastanın \%69'unda AOM, \%25'inde kolesteatomlu KOM, \%6'sinda kolesteatomsuz KOM olduğunu bildirmişlerdir. Çalışmamızdaki hastaların 12'sinde (\%63.1) kolesteatomlu, yedisinde (\%45) kolesteatomsuz KOM tespit edildi. Kolesteatom sonucu oluşan PFP ile ameliyat edilen hastaların fallop kanalı dehissansı sık görülen bir durumdur. Kolesteatomlu tüm hastalarda kanalda defekt bulunmaktaydı. En sık dehissans olan bölge ise literatürle uyumlu olarak timpanik segmentti. Savic ve Djeric ${ }^{[12]}$ çalışmalarında en sık sinir açıklığ́ olan bölgeyi \%92.3 ile timpanik segment olarak bildirmişlerdir. Ikeda ve ark.nın ${ }^{[13]}$ çalışmasında mastoid segment oran $1 \% 26$ olarak bulunmuştur. Bu kolesteatom oranının yüksek olması PFP ile birlikte ek komplikasyonların da bulunmasına bağlandı. Otojen PFP'lerde cerrahi ile \%83'lük kısımda tam, kalan \%17'lik kısımda ise kısmi iyileşme bildirilmiştir. ${ }^{[12]} \mathrm{Bu}$ çalışmadaki otojen PFP'li hastaların 16'sında (\%84) tama yakın iyileşme, ikisinde (\%10) kısmi iyileşme elde edildi, birinde (\%5) ise iyileşme elde edilemedi.

Temporal kemik travması ve buna bağlı fasiyal sinir yaralanması insidansı artan trafik kazaları ve nüfus ile birlikte son yıllarda artmıştır. Travmanın tipi, ani ya da geç başlangıçlı olması, tam ya da kısmi paralizi, travmanın yeri ve elektrofizyolojik testlere dayalı iletim bloğunun şiddeti prognozun ana belirleyicisidir. Hastanın istemli yüz hareketini değerlendirmek ya da erken elektrofizyolojik testleri yapabilmek çoğu hastada acil servislerde ve yoğun bakımda kaldığı sürece genellikle kraniyal travmaya bağlı genel durumunun iyi olmaması nedeniyle mümkün olmamaktadır. Temporal kemik travmaları genelde temporal kemiğin longitudinal kırıklarına neden olur. Transvers kırıklar longitudinal kırıklara kıyasla daha az görülür. Hastalarımızda travmaya bağlı longitudinal kırıklarda en sık neden trafik kazaları oldu. Dört hastamızda ani başlangıçlı PFP görüldü, iki hastamızda da bilinç kaybı uzun süreli olduğu için ani ya da gecikmiş paralizi ayırımı yapılamadı. Longitudinal temporal kemik kırıklarında fasiyal sinir lezyonu çoğunlukla timpanik ve mastoid segmentte görülmektedir. Transvers kırıklarında ise patoloji genellikle labirentin segmenttedir. ${ }^{[14]} \mathrm{Bu}$ çalışmadaki travmatik PFP'li hastaların dördünde (\%67) longitudinal, ikisinde (\%33) transvers tip temporal kemik kırığ1 vardı. Longitudinal kırıkların hepsinde Fallop kanalı ve fasiyal sinirdeki patoloji genikulat gangliyonun distalinde saptand. Transvers kırıkları olan iki hastanın birinde timpanik segmentte lezyon varken diğer hastada timpanik ve mastoid segmentte lezyon yoktu. Odyolojik bulgulara göre labirentin segment lezyonu düşünüldü. Longitudinal kırıklarda genellikle İTIKK, ${ }^{[15]}$ transvers kırıklarda ise SNİK ${ }^{[16]}$ görüldüğü bilinmektedir. Çalışmamızdaki longitudinal kırık bulunan hastaların tümünde kalıcı hafif veya orta derecede İTİK tespit edildi. Transvers kırıkların ikisinde ileri derecede kalıcı SNİK, birinde mikst tip işitme kaybı görüldü. Travmatik PFP'lerde cerrahi sırasında hematom, ödem, kemik parçalarının basısı ve sinir kesileri sıklıkla gözlenmektedir. ${ }^{[17]}$ Ayrıca transvers kırı̆̆ 1 olan hastalarda fasiyal sinirin çevresinde geniş fibrozis belirgindir. ${ }^{[17]}$ Çalışmamızda beş hastada ödem veya hematom ve bir hastada kemik parçalarının neden olduğu bası izlendi. Hiçbir hastada sinir kesisi izlenmedi. Literatürde geçmiş yıllarda, erken dekompresyonu öneren çalışmalar yayınlanmış olsa $\mathrm{da}^{[15]}$ son zamanlarda geç dekompresyon sonuçlarını inceleyen yayınlar bildirilmektedir. ${ }^{[18,19]}$ Uluğ ve Ulubil ${ }^{[18]}$ temporal kemik kır1ğ1 nedeniyle ani başlangıçlı yüz felci oluşan 10 hastaya 14 ila 75 gün arasında farklı zamanlarda cerrahi girişim uygulamışlar ve cerrahinin zamanlamasından bağımsız olarak beş hastanın HB I, dört hastanın HB II olarak iyileştiğini bildirmişlerdir. Quarante ve ark. ${ }^{[19]}$ temporal kemik kırığ 1 nedeniyle fasiyal paralizi oluşan 13 hastaya geç dekompresyon cerrahisi uygulamışlar ve HB I ve HB II iyileşme oranını \%78 olarak bildirmişlerdir. Çalışmamızda geç ortaya çıkan travmatik PFP'lerde konservatif tedavi uygulandı ve bu hastalar çalışmaya dahil edilmedi. Çalışmamızda hepsi erken dönem travmatik PFP olan hastaların dördünde (\%67) iyi, birinde (\%17) orta, birinde (\%17) kötü derecede fonksiyonel iyileşme elde edildi.

Sonuç olarak, fasiyal dekompresyon cerrahisinde zamanlama, fasiyal sinir paralizisinin etyolojisine göre değişmektedir. Travmatik PFP'li hastaların \%67'sinde, KOM'ye bağlı PFP olanların \%84'ünde ve Bell paralizili hastaların ise hepsinde fasiyal sinir fonksiyonlarında tatmin edici iyileşme sağlandı. Fasiyal dekompresyon cerrahisinde uygun zamanlama ve ekip deneyimiyle birlikte başarı yükselmektedir.

\section{Çıkar çakışması beyanı}

Yazarlar bu yazının hazırlanması ve yayınlanması aşamasında herhangi bir çıkar çakı̧̧ması olmadığını beyan etmişlerdir.

\section{Finansman}

Yazarlar bu yazının araştırma ve yazarlık sürecinde herhangi bir finansal destek almadıklarını beyan etmişlerdir. 


\section{KAYNAKLAR}

1. Kowalska-Ludwicka K, Cala J, Grobelski B, Sygut D, Jesionek-Kupnicka D, Kolodziejczyk M, et al. Modified bacterial cellulose tubes for regeneration of damaged peripheral nerves. Arch Med Sci 2013;9:527-34.

2. Altun I, Çıralık H. Histopathological Effects of Tissue Adhesives on Experimental Peripheral Nerve Transection Model in Rats. J Korean Neurosurg Soc 2015;58:504-7.

3. Cramer HB, Kartush JM. Testing facial nerve function. Otolaryngol Clin North Am 1991;24:555-70.

4. Cramer HB, Kartush JM. Testing facial nerve function. Otolaryngol Clin North Am 1991;24:555-70.

5. House JW, Brackmann DE, Facial nerve grading system. Otolaryngology-Head \& Neck Surgery 1985;93:146-7.

6. May M, Blumenthal F, Klein SR. Acute Bell's palsy: prognostic value of evoked electromyography, maximal stimulation, and other electrical tests. Am J Otol 1983;5:1-7.

7. Fisch U. Prognostic value of electrical tests in acute facial paralysis. Am J Otol 1984;5:494-8.

8. Aoyagi M, Koike Y, Ichige A. Results of facial nerve decompression. Acta Otolaryngol Suppl 1988;446:101-5.

9. Yasumura S, Watanabe Y, Aso S, Asai M, Ito M, Mizukoshi K. Result of decompression surgery in late-stage severe facial paralysis. Acta Otolaryngol Suppl 1993;504:134-6.

10. Gantz BJ, Rubinstein JT, Gidley P, Woodworth GG. Surgical management of Bell's palsy. Laryngoscope
1999;109:1177-88.

11. Özbek MC, Somuk BT, Tuna EU, Çiftci O, Özdem C. Kolesteatomlu kronik otitis mediada fasiyal paralizi: Tedavi ve sonuçlar. KBB ve BBC Dergisi 2008;16:72-7.

12. Savić DL, Djerić DR. Facial paralysis in chronic suppurative otitis media. Clin Otolaryngol Allied Sci 1989;14:515-7.

13. Ikeda M, Nakazato H, Onoda K, Hirai R, Kida A. Facial nerve paralysis caused by middle ear cholesteatoma and effects of surgical intervention. Acta Otolaryngol 2006;126:95-100.

14. Cannon CR, Jahrsdoerfer RA. Temporal bone fractures. Review of 90 cases. Arch Otolaryngol 1983;109:285-8.

15. Fisch U. Facial paralysis in fractures of the petrous bone. Laryngoscope 1974;84:2141-54.

16. Darrouzet V, Duclos JY, Liguoro D, Truilhe Y, De Bonfils C, Bebear JP. Management of facial paralysis resulting from temporal bone fractures: Our experience in 115 cases. Otolaryngol Head Neck Surg 2001;125:77-84.

17. Yetiser S. Total facial nerve decompression for severe traumatic facial nerve paralysis: a review of 10 cases. Int J Otolaryngol 2012;2012:607359.

18. Ulug T, Arif Ulubil S. Management of facial paralysis in temporal bone fractures: a prospective study analyzing 11 operated fractures. Am J Otolaryngol 2005;26:230-8.

19. Quaranta A, Campobasso G, Piazza F, Quaranta N, Salonna I. Facial nerve paralysis in temporal bone fractures: outcomes after late decompression surgery. Acta Otolaryngol 2001;121:652-5. 